\title{
Tilt of the columnar microstructure in off- normally deposited thin films using highly ionized vapor fluxes
}

Viktor Elofsson, Daniel Magnfält, M Samuelsson and Kostas Sarakinos

\author{
Linköping University Post Print
}

\section{Tweet}

N.B.: When citing this work, cite the original article.

Original Publication:

Viktor Elofsson, Daniel Magnfält, M Samuelsson and Kostas Sarakinos, Tilt of the columnar microstructure in off-normally deposited thin films using highly ionized vapor fluxes, 2013, Journal of Applied Physics, (113), 17, 7 pages.

http://dx.doi.org/10.1063/1.4804066

Copyright: American Institute of Physics (AIP) http://www.aip.org/

Postprint available at: Linköping University Electronic Press http://urn.kb.se/resolve?urn=urn:nbn:se:liu:diva-94608 


\title{
Tilt of the columnar microstructure in off-normally deposited thin films using highly ionized vapor fluxes
}

\author{
V. Elofsson, ${ }^{1, a)}$ D. Magnfält, ${ }^{1}$ M. Samuelsson, ${ }^{2}$ and K. Sarakinos ${ }^{1}$ \\ ${ }^{1}$ Plasma \& Coatings Physics Division, Department of Physics, Chemistry and Biology (IFM), \\ Linköping University, SE-581 83 Linköping, Sweden \\ ${ }^{2}$ Impact Coatings, Westmansgatan 29, SE-582 16 Linköping, Sweden
}

(Received 2 January 2013; accepted 22 April 2013; published online 6 May 2013)

\begin{abstract}
The tilt of the columnar microstructure has been studied for $\mathrm{Cu}$ and $\mathrm{Cr}$ thin films grown offnormally using highly ionized vapor fluxes, generated by the deposition technique high power impulse magnetron sputtering. It is found that the relatively large column tilt (with respect to the substrate normal) observed for $\mathrm{Cu}$ films decreases as the ionization degree of the deposition flux increases. On the contrary, $\mathrm{Cr}$ columns are found to grow relatively close to the substrate normal and the column tilt is independent from the ionization degree of the vapor flux when films are deposited at room temperature. The Cr column tilt is only found to be influenced by the ionized fluxes when films are grown at elevated temperatures, suggesting that film morphology during the film nucleation stage is also important in affecting column tilt. A phenomenological model that accounts for the effect of atomic shadowing at different nucleation conditions is suggested to explain the results. C 2013 AIP Publishing LLC. [http://dx.doi.org/10.1063/1.4804066]
\end{abstract}

\section{INTRODUCTION}

Thin films grown by physical vapor deposition (PVD) techniques often exhibit a columnar microstructure. The latter emerges when thermodynamics and kinetics favor VolmerWeber type growth, which yields formation of spatially separated atomic nuclei. As more atoms arrive at the film surface, the nuclei grow in size, coalesce, and may develop in a columnar fashion. If the deposition flux impinge at an angle other than zero with respect to the substrate normal, the initially formed nuclei shadow the area behind them, causing no deposition to occur in the shadowed region as more atoms are supplied from the vapor. ${ }^{1,2}$ This leads to formation of underdense structures, in which spatially separated columns are tilted towards the direction of the incident vapor. ${ }^{1,2}$ Off-normal growth is commonly encountered when depositing on threedimensional objects using directional fluxes. In this case, shadowing can be detrimental for the film quality if uniform and dense coatings are required. The off-normal deposition can also be intentionally exploited to grow nanostructured films - this approach is known as glancing angle deposition (GLAD)_engineering the columnar structure into, e.g., helical, vertical posts, and zig-zag patterns, ${ }^{1-3}$ or into combinations thereof. ${ }^{4}$ Some of the most notable applications of these nanostructured films are as anti-reflective coatings ${ }^{5}$ and threedimensional photonic crystals. ${ }^{6}$

Control of column tilt and separation is a prerequisite for tailoring the properties and the functionality in offnormally deposited films. ${ }^{1}$ Variation of the composition ${ }^{7}$ or the spatial distribution of the deposited material, e.g., by employing more than one material source ${ }^{8,9}$ or by varying the deposition pressure, ${ }^{10}$ can influence the degree of column tilt. The latter may also be affected by changing the surface

\footnotetext{
a) Author to whom correspondence should be addressed. Electronic mail: vikjo@ifm.liu.se.
}

mobility of the film forming species, e.g., by varying the growth temperature ${ }^{11,12}$ and the deposition rate. ${ }^{13,14}$ An ionized deposition flux can also be employed to influence the angular distribution of the deposited material, since the trajectories of charged species can be manipulated by the use of electric and/or magnetic fields. ${ }^{15-18}$ A technique that can be used to generate highly ionized deposition fluxes is high power impulse magnetron sputtering (HiPIMS). ${ }^{19-23}$ Previously, HiPIMS has been employed for the deposition of Ta films on substrates placed at an angle of $90^{\circ}$ with respect to the sputtering target normal, yielding films with columns positioned along the substrate surface normal. ${ }^{24}$ On the other hand, the columns of films deposited using direct current magnetron sputtering (DCMS), which yields relatively small degrees of ionization of the sputtered material, were inclined towards the incoming flux. ${ }^{24}$ Similar observations were made for off-normally deposited $\mathrm{Cr}$ films where it was found that the tilt of the columns approached the substrate normal as the degree of ionization of the sputtered material was increased by appropriate tuning of the HiPIMS process parameters. ${ }^{25}$ The importance of these findings for technologically relevant applications has manifested itself in the uniform filling of nanometer- to micrometer-sized trenches by various metallic films ${ }^{26,27}$ as well as in the growth of uniform ceramic coatings on cutting tools of complex geometry. ${ }^{28}$ The ability to control column tilt when employing highly ionized fluxes in an off-normal deposition arrangement was explained by the deflection of ions closer to the substrate normal as a result of the high negative bias potential of several tens or hundreds of volts that was applied to the substrates in the aforementioned studies. Substrate bias may though not only change incidence angle of the ions but also accelerates those ions towards the growing film. Energetic ion bombardment is known to increase surface diffusion, ${ }^{29}$ create surface defects that act as preferential nucleation sites, ${ }^{30}$ disrupt small atomic clusters, and thereby 
increase the nucleation density. ${ }^{31,32}$ Furthermore, when altering the HiPIMS process parameters to vary the ionization degree of the sputtered materials, the film deposition rate is also influenced. ${ }^{20}$ All the above-mentioned factors are known to affect the kinetic conditions during film nucleation and growth. The correlations between nucleation and growth kinetics, and the column tilt in films grown off-normally from highly ionized fluxes remain to be investigated.

In the present study, we seek to contribute to the understanding of the fundamental mechanisms that determine the column tilt in off-normally deposited films using highly ionized fluxes. We implement a strategy that enables us to vary the degree of ionization of the sputtered material and at the same time keep the energy of the deposited species at a minimum level. Films are also grown at process conditions that yield different degrees of ionization of the sputtered material while the film deposition rate is kept constant in order to assess the effect of the latter on the column tilt. Moreover, the importance of the nucleation and post nucleation film formation stages at different growth kinetic conditions and at well-controlled ionization degrees of the deposition flux is investigated with respect to the column tilt. Monte Carlo simulations are also utilized to study the effect of the deposition conditions on the energy distributions and the angular spread of the sputtered species. A phenomenological model that accounts for the effect of nucleation characteristics and direction of the deposition flux on the atomic shadowing during off-normal film growth is proposed to explain the results.

\section{EXPERIMENTAL PROCEDURE AND STRATEGY}

\section{A. General experimental procedure}

Films were synthesized in a chamber with a base pressure of $8 \times 10^{-6} \mathrm{~Pa}$. The chamber was equipped with two magnetrons on which circular targets with a diameter of $50.8 \mathrm{~mm}$ were mounted. One of the magnetrons was facing the substrate, while the other was placed at an angle of $90^{\circ}$ with respect to the substrate surface normal as illustrated in Fig. 1. The distance between the stationary substrate and the target was about $90 \mathrm{~mm}$ for both magnetrons. Si (001) wafers covered by a $\sim 2 \mathrm{~nm}$ native oxide were used as substrates. The deposition rate was monitored by a quartz crystal microbalance $(\mathrm{QCM})$ mounted close to the position of the substrate. Argon, with a minimum purity of $99.9997 \%$, was employed as sputtering gas to achieve a working pressure of 0.7 Pa. $\mathrm{Cu}$ and $\mathrm{Cr}$ were chosen as target materials, since the

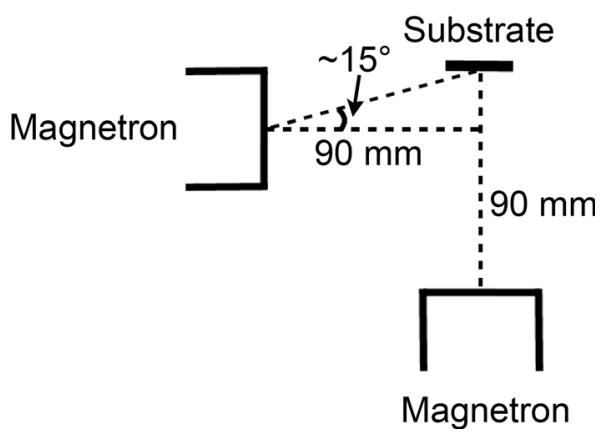

FIG. 1. Schematic of the experimental setup in cross-sectional view. respective films exhibit distinctly different growth behaviors as dictated by kinetics. This can be understood by taking into account the differences in the melting temperatures between $\mathrm{Cu}$ and $\mathrm{Cr}$ (1358 and $2180 \mathrm{~K}$, respectively), ${ }^{33}$ which leads to a higher mobility of the $\mathrm{Cu}$ adatoms at the same growth temperature.

Films were deposited using HiPIMS, as well as DCMS, for reference. The HiPIMS depositions were performed using a SPIK 1000A (Melec GmbH) pulsing unit fed by a direct current (DC) generator (MDX Pinnacle, Advanced Energy). The process time dependent voltage and current waveforms were measured using a 1:100 voltage divider and a current clamp (Chauvin Arnoux C160), respectively, and monitored on a digital oscilloscope (Tektronix TDS 520 C). These waveforms were employed to calculate the average target power. For the DCMS experiments, an Advanced Energy MDX $1 \mathrm{~K}$ DC generator was utilized. The discharge power, voltage, and current were obtained directly from the readout of the generator. The effect of the deposition conditions on the column tilt as well as the film thickness were evaluated by scanning electron microscopy (SEM, LEO 1550 Gemini) observations of cryofractured cross-sectional samples. The column tilt angles were measured from the substrate surface normal, i.e., an increase in the measured angle signifies columns tilted further away from the substrate surface normal.

Due to the ductile nature of $\mathrm{Cu}$, poor adhesion between film and substrate was in many cases encountered during preparation of samples for SEM analysis. To improve the adhesion and thus the sample preparation efficiency, a number of substrates were coated with a $\sim 120 \mathrm{~nm}$ Ti adhesion layer prior to the deposition of the $\mathrm{Cu}$ film. The Ti layer was grown employing DCMS at a constant average power of $100 \mathrm{~W}$ from the magnetron facing the substrate. Samples were also grown directly on the bare $\mathrm{Si}$ substrates and carefully prepared to study possible effects of the Ti layer on the column tilt. Although not explicitly needed, Cr films were grown both with and without the Ti layer for comparison purposes. No influence of the Ti layer on the tilt of the columnar microstructure was found neither for $\mathrm{Cu}$ nor for $\mathrm{Cr}$ films.

\section{B. Specific experimental strategy}

In total, five sets of samples were deposited as detailed below and summarized in Table I.

Set 1: In this set, $\mathrm{Cu}$ and $\mathrm{Cr}$ films with a thickness of

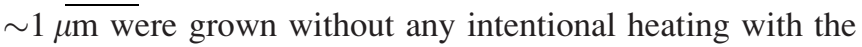
substrate holder kept grounded, aiming at minimizing the energy of the impinging ions. Depositions were done by HiPIMS at a constant average power of 200 and $150 \mathrm{~W}$ for

TABLE I. Summary of all experimental sets.

\begin{tabular}{lcccc}
\hline \hline Set & Material & Method & $\mathrm{I}_{\mathrm{Tpd}}\left(\mathrm{Acm}^{-2}\right)$ & Remarks \\
\hline 1 & $\mathrm{Cu}, \mathrm{Cr}$ & DCMS/HiPIMS & $0.2-2.2$ & Constant avg. power \\
2 & $\mathrm{Cu}$ & HiPIMS & $0.2-1.4$ & Constant avg. dep. rate \\
3 & $\mathrm{Cu}$ & HiPIMS & $2.0 / 0.2$ & Varied $\mathrm{I}_{\mathrm{Tpd}}$ during growth \\
4 & $\mathrm{Cr}$ & DCMS/HiPIMS & 1.0 & Elevated temp. \\
5 & $\mathrm{Cr}$ & DCMS & N/A & Varied temp. during growth \\
\hline \hline
\end{tabular}


$\mathrm{Cu}$ and $\mathrm{Cr}$, respectively. The pulse length was $50 \mu \mathrm{s}$, while the pulsing frequency was varied between 250 and $2000 \mathrm{~Hz}$. Within this frequency range, the peak target current density $\left(\mathrm{I}_{\mathrm{Tpd}}\right)$ was found to take values from 0.2 to $2.2 \mathrm{Acm}^{-2}$ (increasing with decreasing frequency). The degree of ionization of the sputtered material in HiPIMS is known to depend strongly on $\mathrm{I}_{\mathrm{Tpd}}$ where a larger value results in a larger ionization degree. ${ }^{20}$ Thus, variation of this quantity enables one to tune the amount of ionized species available for deposition and study their implications on the film growth. For reference, films were also deposited by DCMS at a constant average power of 200 and $150 \mathrm{~W}$ for $\mathrm{Cu}$ and $\mathrm{Cr}$, respectively.

Set 2: An increase in $\mathrm{I}_{\mathrm{Tpd}}$ is known to result in a reduction of the film deposition rate. ${ }^{20,34,35}$ To study its effect on the column tilt, films were deposited using the procedure described in set 1 , with the only difference being that the film deposition rate, as measured by the QCM, was held constant by adjusting the average power applied to the target. The qualitative validity of the values delivered by the QCM was confirmed by cross-sectional SEM observations.

Set 3: Variation of $\mathrm{I}_{\mathrm{Tpd}}$ and thus of the degree of ionization of the sputtered material affects also the conditions of energetic bombardment that the film experiences during growth. The latter, in turn, may affect the adatom mobility and, through this, nucleation and post nucleation characteristics. Therefore, a $\sim 500 \mathrm{~nm} \mathrm{Cu}$ film was grown at a $\mathrm{I}_{\mathrm{Tpd}}$ value of $2.0 \mathrm{Acm}^{-2}$ directly followed by another $\sim 500 \mathrm{~nm}$ at $0.2 \mathrm{Acm}^{-2}$, thus using the first $500 \mathrm{~nm}$ as growth template. The obtained column tilt was subsequently compared to that in films from set 1 grown at a constant $\mathrm{I}_{\text {Tpd }}$.

Set 4: As mentioned in Sec. II A, the kinetic conditions during growth of $\mathrm{Cu}$ and $\mathrm{Cr}$ are distinctly different. In this set, Cr films were deposited using DCMS at elevated temperatures, ranging from room temperature to $340^{\circ} \mathrm{C}$. The highest temperature corresponds to a homologous temperature $\left(\mathrm{T}_{\mathrm{s}} / \mathrm{T}_{\mathrm{m}}\right)$ of $\sim 0.28$ which is comparable to the $\mathrm{T}_{\mathrm{s}} / \mathrm{T}_{\mathrm{m}}$ value $(\sim 0.22)$ during growth of $\mathrm{Cu}$ at room temperature. Thus, the effect of growth kinetics on the column tilt could be explicitly investigated while maintaining a well-defined and relatively small degree of ionization by employing DCMS. In addition, a $\mathrm{Cr}$ film was also grown using HiPIMS $\left(\mathrm{I}_{\mathrm{Tpd}}=1.0 \mathrm{Acm}^{-2}\right)$ at $340{ }^{\circ} \mathrm{C}$.

Set 5: In this set, a $\sim 1 \mu \mathrm{m} \mathrm{Cr}$ film was grown by DCMS by increasing the deposition temperature from room temperature to $340^{\circ} \mathrm{C}$ after depositing $\sim 500 \mathrm{~nm}$. Subsequently, the column tilt in this film was compared to that of films grown using DCMS at constant temperature (set 4) seeking to shed light on the relevance of nucleation and post nucleation characteristics for the column tilt.

\section{Simulation of particle transport}

In order to investigate possible effects on the column tilt arising from changes in the energies and trajectories of sputtered species due to collisions with the buffer gas atoms, the energy and angular distributions of the sputtered species at the substrate were estimated employing the Monte Carlo based SIMTRA code. ${ }^{36}$ A screened Coulomb potential
(Molière type) was used to describe the interactions between the sputtered species $(\mathrm{Cu}$ and $\mathrm{Cr}$ ) and the buffer gas. The gas temperature was set to $300 \mathrm{~K}$. The initial energy and angular distributions of the sputtered species were obtained from the SRIM code,${ }^{37}$ using an incidence energy of the impinging $\mathrm{Ar}^{+}$ions equal to the discharge voltages used in the DCMS and HiPIMS depositions.

\section{RESULTS AND DISCUSSION}

The cross-sectional SEM micrographs of two representative $\mathrm{Cu}$ films deposited at a constant average power of $200 \mathrm{~W}$ by DCMS and by HiPIMS, using a $\mathrm{I}_{\text {Tpd }}$ of $2.1 \mathrm{Acm}^{-2}$ (corresponding to a pulsing frequency of $250 \mathrm{~Hz}$ ), are shown in Figs. 2(a) and 2(b), respectively. In both cases, an underdense columnar microstructure is observed with columns tilted towards the incident deposition flux (indicated by arrows). The tilt angle of the columns in the sample deposited by DCMS is $\sim 53^{\circ}$ which is larger than the angle of the columns in the HiPIMS grown sample $\left(\sim 38^{\circ}\right)$. The corresponding micrographs for $\mathrm{Cr}$ films grown at a constant average power of $150 \mathrm{~W}$ are also presented in Fig. 2 (Figs. 2(c) and 2(d) for DCMS and HiPIMS $\left(\mathrm{I}_{\mathrm{Tpd}}=1.4 \mathrm{Acm}^{-2}\right)$ grown films, respectively). Similarly to the $\mathrm{Cu}$ films, the $\mathrm{Cr}$ films exhibit an underdense microstructure titled towards the sputtering source. In contrast to the $\mathrm{Cu}$ films, both $\mathrm{Cr}$ films exhibit the same column tilt angle of $\sim 27^{\circ}$ irrespective of deposition method.

Fig. 3 summarizes the effect of $I_{T p d}$ on the tilt angle of $\mathrm{Cu}$ (circles) and $\mathrm{Cr}$ (squares) films grown at a constant average power, i.e., the samples that correspond to set 1 . For films grown by DCMS (indicated with arrows in Fig. 3), the $\mathrm{I}_{\text {Tpd }}$ was taken to be equal to the average target current density during deposition. Fig. 3 shows that the tilt angle of the columns in the $\mathrm{Cu}$ films decreases linearily from $53^{\circ}$ to $37^{\circ}$ as the $\mathrm{I}_{\mathrm{Tpd}}$ is increased from 0.02 to $2.2 \mathrm{Acm}^{-2}$. This trend is in agreement with previous reports. ${ }^{24,25}$ The same behaviour
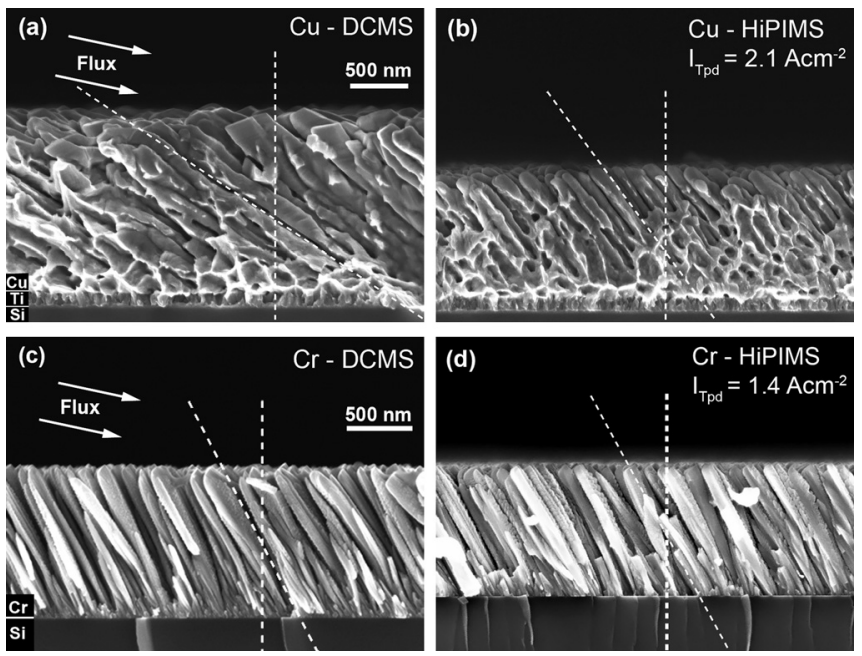

FIG. 2. Cross-sectional SEM micrographs showing typical column tilt in $\mathrm{Cu}$ films grown at a constant average power of $200 \mathrm{~W}$ using (a) DCMS and (b) HiPIMS and Cr films grown at a constant average power of $150 \mathrm{~W}$ using (c) DCMS and (d) HiPIMS. The substrate normal and the column tilt are indicated by dashed lines. 


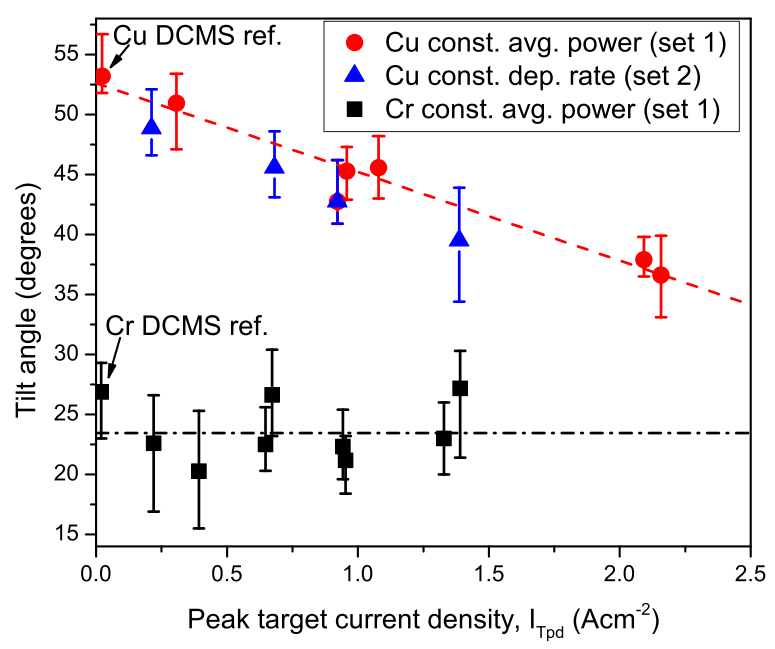

FIG. 3. Column tilt angle with respect to the substrate surface normal as a function of the peak target current density ( $\mathrm{I}_{\mathrm{Tpd}}$ ) for $\mathrm{Cu}$ (circles) and $\mathrm{Cr}$ (squares) films grown at constant average power (set 1) and $\mathrm{Cu}$ films grown at constant deposition rate (triangles, set 2 ). The lines are drawn as a guide to the eye.

is not seen for the $\mathrm{Cr}$ films, where no significant influnce of $\mathrm{I}_{\mathrm{Tpd}}$ on the column tilt is observed.

The increase of $\mathrm{I}_{\mathrm{Tpd}}$ from 0.02 to $2.2 \mathrm{Acm}^{-2}$ during the growth of $\mathrm{Cu}$ films resulted in a decrease of the film growth rate by about $30 \%$. To exclude any influence of the deposition rate on the column tilt, $\mathrm{Cu}$ films were also deposited at a constant deposition rate, equal to the lowest value obtained by HiPIMS, while varying $\mathrm{I}_{\mathrm{Tpd}}$ from 0.2 to $1.4 \mathrm{Acm}^{-2}$ (set 2). The column tilt values measured in these samples are also plotted in Fig. 3 (triangles). It is seen that the tilt angle of $\mathrm{Cu}$ samples from set 1 (constant average power) and set 2 (constant average deposition rate) exhibit the same trend. We therefore infer that, for the conditions employed in the present study, the column tilt is primarly governed by the interactions of ionized species with the surface of the growing film rather than by the arrival rate of the film forming species.

Fig. 4 presents the cross-sectional SEM micrograph of a $\sim 1 \mu \mathrm{m} \mathrm{Cu}$ film where $\mathrm{I}_{\mathrm{Tpd}}$ is decreased from 2.0 to $0.2 \mathrm{Acm}^{-2}$ after depositing $\sim 500 \mathrm{~nm}$ (set 3). Like the

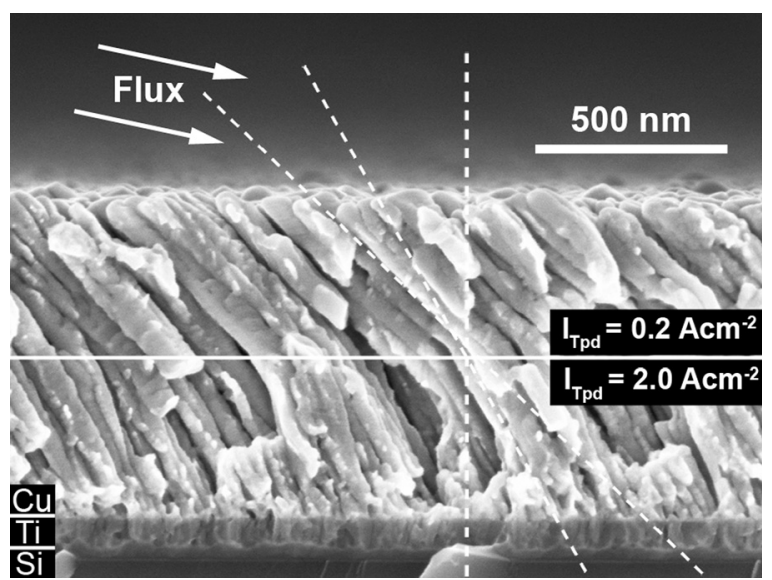

FIG. 4. Cross-sectional SEM micrograph showing columnar tilt of a $\mathrm{Cu}$ film where the peak target current density $\left(\mathrm{I}_{\mathrm{Tpd}}\right)$ is abruptly decreased from 2.0 to $0.2 \mathrm{Acm}^{-2}$ half way through the deposition (indicated by the horizontal solid line). The substrate normal and the column tilts are indicated by dashed lines. previous micrographs, the film exhibits an underdense structure with columns tilted towards the incident flux. The tilt angle increases abruptly from $\sim 27^{\circ}$ to $\sim 48^{\circ}$ when $\mathrm{I}_{\mathrm{Tpd}}$ decreases. The change of the tilt angle $\left(\sim 21^{\circ}\right)$ is in fair agreement with the differences observed for samples grown at a constant $\mathrm{I}_{\mathrm{Tpd}}$ of 2.2 and $0.3 \mathrm{Acm}^{-2}\left(\sim 14^{\circ}\right)$ from Fig. 3. This indicates that the reason for the different column tilt angles of the $\mathrm{Cu}$ films observed in Fig. 3 cannot be attributed to possible differences in nucleation characteristics (i.e., nuclei density) induced when the film encounters different energetic bombardment conditions at the various $\mathrm{I}_{\mathrm{Tpd}}$. Instead, the decrease of column tilt upon increasing $\mathrm{I}_{\mathrm{Tpd}}$ may be attributed to the increase of the ionization degree that implies that a larger fraction of the deposited species is deflected towards the substrate normal due to the potential difference between plasma and grounded substrate (see, e.g., Ref. 24), which typically is of the order of $1-5 \mathrm{~V} .^{38-41}$ Moreover, energetic species impinging onto the substrate in a direction relatively close to that of the substrate normal (which is the case for ionized species in the present study) transfer energy and momentum to the impact site, which may enhance diffusion lengths of adatoms near the impact site in an isotropic manner. This in turn may promote downhill diffusion from island facets ${ }^{42}$ reducing surface roughness and shadowing effects. These species may also provide the energy for adatoms to overcome the activation barrier for diffusion from the tip of the columns to the shadowed area (the driving force for this diffusion is the concentration gradient in adatom density between the tip of the column and the shadowed area, see Ref. 1). Both these effects may account for the decrease of the column tilt when increasing $\mathrm{I}_{\text {Tpd }}$. At conditions of off-normal growth, energetic species may also impinge onto the substrate at an oblique angle exhibiting preferential diffusion to the direction of the deposition flux. ${ }^{43}$ In this case, the energy available for diffusion (and thus the diffusion length) depends on the initial energy of the incident species. In the present study, species that are mainly subjected to this type of directional diffusion are sputtered atoms and ions with energies significantly larger than that obtained from the acceleration field between plasma and substrate. In general, ion energies increase with increasing $\mathrm{I}_{\mathrm{Tpd}},{ }^{44}$ which means that an enhanced directional diffusion may partially explain the change of column tilt when increasing $\mathrm{I}_{\mathrm{Tpd}}$ in Fig. 3. This is not the case for atoms since Monte Carlo simulations have shown that the energy of sputtered atoms is almost independent of the deposition conditions.

The cross-sectional micrographs of two representative Cr films grown by DCMS $\left(\mathrm{I}_{\mathrm{Tpd}}=0.02 \mathrm{Acm}^{-2}\right)$ at $180^{\circ} \mathrm{C}$ and $340^{\circ} \mathrm{C}$ are shown in Figs. 5(b) and 5(c), respectively. The micrograph that corresponds to a film grown at room temperature (originally Fig. 2(c)) is also presented in Fig. 5(a), for reference. An underdense structure is seen in all films, and the column tilt significantly increases from $\sim 27^{\circ}$ via $\sim 43^{\circ}$ to $\sim 50^{\circ}$ as the growth temperature increases from room temperature $\left(20^{\circ} \mathrm{C}\right)$ via $180^{\circ} \mathrm{C}$ to $340^{\circ} \mathrm{C}$, respectively. It is also notable that the width of the columns increases with temperature, indicating a smaller nuclei density.

Fig. 6 summarizes the effect of growth temperature (in terms of $\mathrm{T}_{\mathrm{s}} / \mathrm{T}_{\mathrm{m}}$ ) on the column tilt of $\mathrm{Cr}$ films grown by 

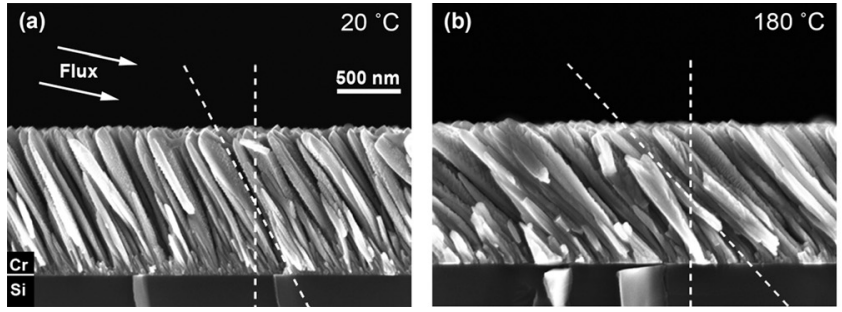

DCMS (squares) and HiPIMS at $\mathrm{I}_{\mathrm{Tpd}}=1.0 \mathrm{Acm}^{-2}$ (circles, set 4). Values for $\mathrm{Cu}$ films grown by DCMS (triangles) and HiPIMS at $\mathrm{I}_{\mathrm{Tpd}}=2.2 \mathrm{Acm}^{-2}$ (diamonds) are also presented in the figure, for reference. It is seen that the column tilt of the $\mathrm{Cr}$ films grown by DCMS increases from $\sim 27^{\circ}$ to $\sim 50^{\circ}$ as $T_{s} / T_{m}$ is increased from 0.13 to 0.28 . Increasing $T_{s} / T_{m}$ within this range affects mostly surface diffusion, ${ }^{45}$ which in accordance to what has been discussed previously should drive adatoms to diffuse from the column tips towards shadowed areas and yield a smaller tilt angle. ${ }^{1,11,12}$ Since the opposite behavior is observed, a different mechanism (discussed below in the present section) has to be invoked to explain the results. Furthermore, in Fig. 6, it is seen that at a $\mathrm{T}_{\mathrm{s}} / \mathrm{T}_{\mathrm{m}}$ of 0.28 the tilt angle of the HiPIMS $\left(\mathrm{I}_{\mathrm{Tpd}}=1.0\right.$ $\mathrm{Acm}^{-2}$ ) grown film is $\sim 19^{\circ}$ smaller than that of the DCMS counterpart, i.e., a decrease of the $\mathrm{Cr}$ column tilt is observed when using highly ionized fluxes at a $\mathrm{T}_{\mathrm{s}} / \mathrm{T}_{\mathrm{m}}$ of 0.28 as opposed to the case of 0.13 . This behavior is in qualitative agreement with the results obtained for $\mathrm{Cu}$ films at a $\mathrm{T}_{\mathrm{s}} / \mathrm{T}_{\mathrm{m}}$ of 0.22 .

Fig. 7 presents cross-sectional SEM micrographs of a DCMS grown $\mathrm{Cr}$ film where the temperature during deposition is increased from room temperature $\left(20^{\circ} \mathrm{C}\right)$ to $340^{\circ} \mathrm{C}$ approximately half-way through the deposition (set 5). Both micrographs are obtained from the same film but at different positions. In Fig. 7(a) close to all columns grow with the same angle of $\sim 30^{\circ}$ throughout the entire deposition, which is in excellent agreement with the column tilt for the $\mathrm{Cr}$ films

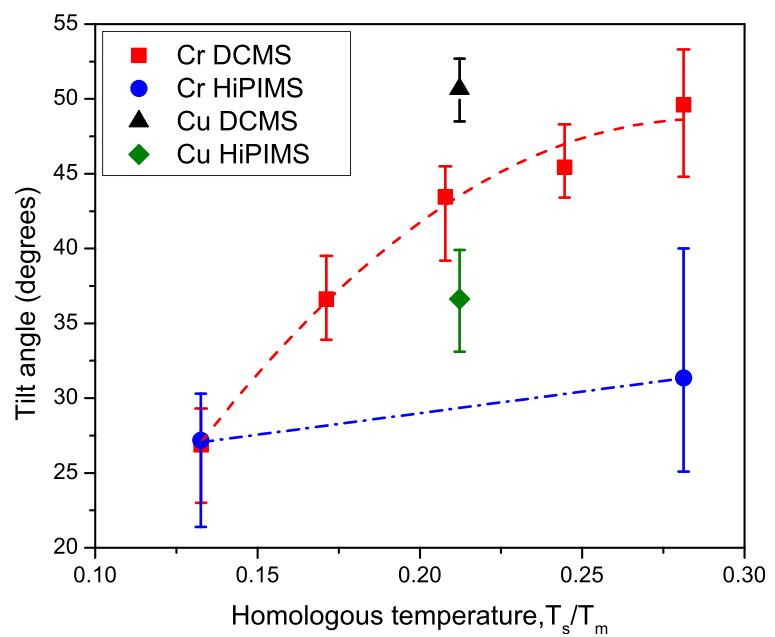

FIG. 6. Column tilt angle with respect to the substrate surface normal as a function of the homologous temperature $\left(\mathrm{T}_{\mathrm{s}} / \mathrm{T}_{\mathrm{m}}\right)$ for $\mathrm{Cr}$ films grown by DCMS (squares) and HiPIMS (circles) at a constant average power (set 4). The corresponding angles for $\mathrm{Cu}$ films grown by DCMS (triangles) and HiPIMS at $\mathrm{I}_{\mathrm{Tpd}}=2.2 \mathrm{Acm}^{-2}$ (diamonds) are also included for reference. The lines are drawn as a guide to the eye.

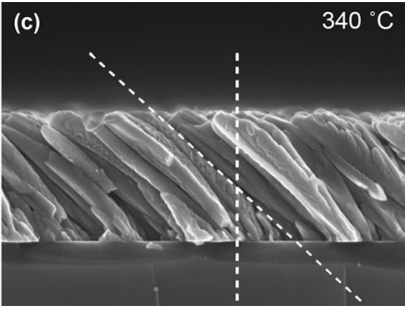

FIG. 5. Cross-sectional SEM micrographs of $\mathrm{Cr}$ films grown using DCMS at (a) room temperature $\left(20^{\circ} \mathrm{C}\right)$, (b) $180^{\circ} \mathrm{C}$, and (c) $340^{\circ} \mathrm{C}$. The substrate normal and the column tilt are indicated by dashed lines. grown at room temperature $\left(\sim 27^{\circ}\right)$. At other positions in the film, as can be seen in Fig. 7(b), a significant increase in tilt of $\sim 15^{\circ}$ is observed after the temperature is increased. This change occurs when two (or more) spatially separated columns merge to form one new, larger column.

The quantity $\mathrm{T}_{\mathrm{s}} / \mathrm{T}_{\mathrm{m}}$ is known to affect the adatom diffusion, resulting in different nucleation characteristics. An increased value of $\mathrm{T}_{\mathrm{s}} / \mathrm{T}_{\mathrm{m}}$ yields larger and fewer nuclei with a larger spatial separation for the same substrate coverage. $^{46,47}$ The latter implies that a larger area behind an individual nucleus is shadowed, as depicted in Fig. 8. This allows the growth to continue more in a direction towards the flux and thus yield a larger column tilt. For $\mathrm{Cu}$ grown at room temperature $\left(\mathrm{T}_{\mathrm{s}} / \mathrm{T}_{\mathrm{m}}=0.22\right)$, the nuclei density is expected to be relatively small and in accordance with Fig. 8 result in a large column tilt. In the case of $\mathrm{Cr}$ grown at room temperature $\left(\mathrm{T}_{\mathrm{s}} / \mathrm{T}_{\mathrm{m}}=0.13\right)$, the nuclei density is, in contrast,
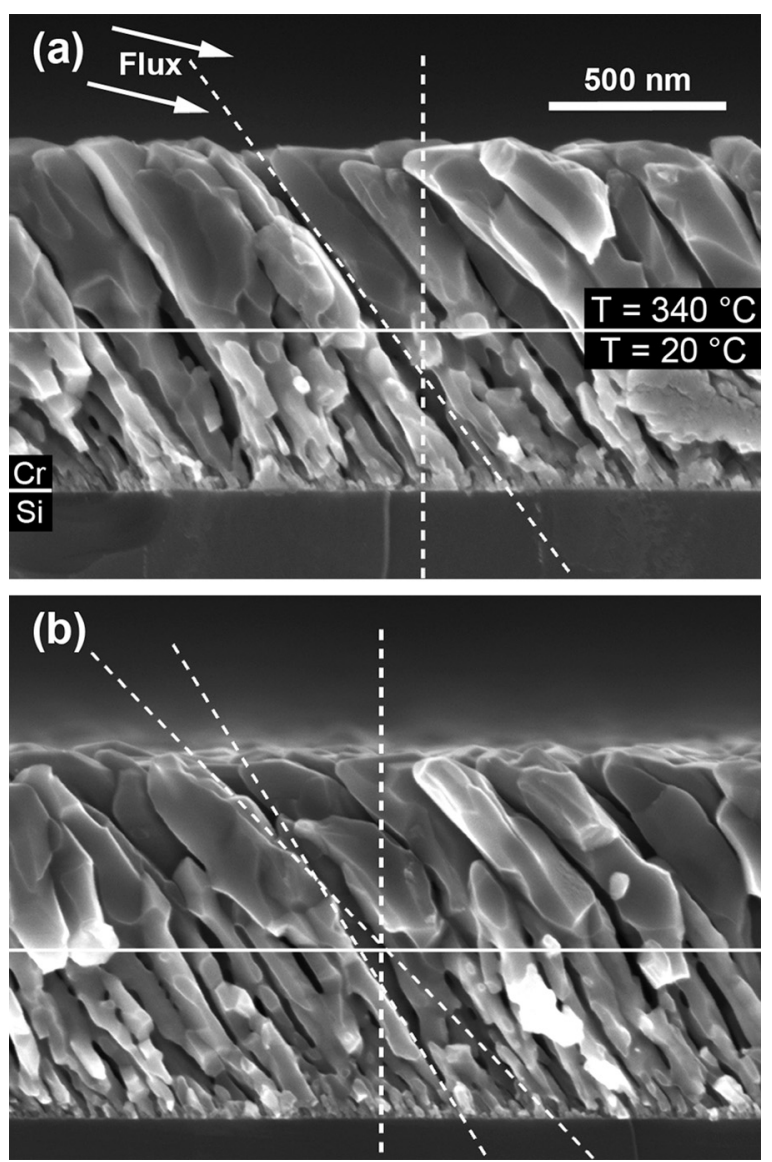

FIG. 7. Cross-sectional SEM micrographs of a $\mathrm{Cr}$ film (grown using DCMS) where the growth temperature was increased from room temperature $\left(20^{\circ} \mathrm{C}\right)$ to $340^{\circ} \mathrm{C}$ half-way through the deposition (indicated by the solid horizontal line). (a) and (b) are taken from the same film. 


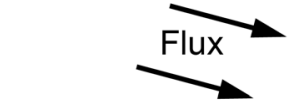

Nucleation
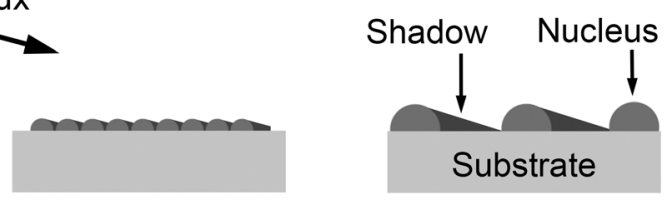

Film growth
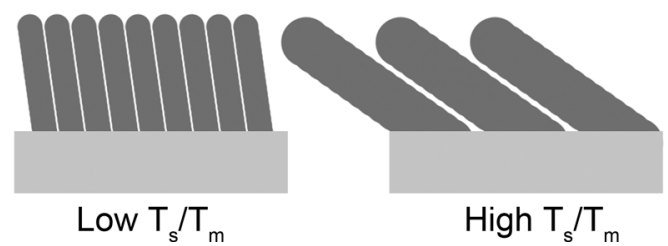

$\operatorname{High} \mathrm{T}_{\mathrm{s}} / \mathrm{T}_{\mathrm{m}}$

FIG. 8. Schematic drawing of the column tilt evolution depending on the initial nuclei conditions for low and high homologous temperatures $\left(\mathrm{T}_{\mathrm{s}} / \mathrm{T}_{\mathrm{m}}\right)$.

expected to be relatively large. As depicted in Fig. 8, this means that growth can only continue at the very top most part of each nucleus, yielding a small column tilt. We suggest that this is the reason for the difference in column tilt observed between $\mathrm{Cu}$ and $\mathrm{Cr}$ when grown at room temperature (see Figs. 2(a) and 2(c)). Another factor that can influence the column tilt is the angular spread of the incidence flux. Monte Carlo simulations showed that the normalized angular distributions of $\mathrm{Cu}$ and $\mathrm{Cr}$ at the substrate were nearly identical, with an average incidence angle of $\sim 52^{\circ}$. Therefore, we infer that the transport of the different species through the plasma cannot induce the large difference in tilt angle observed between $\mathrm{Cu}$ and $\mathrm{Cr}$ columns. Increase of the substrate temperature during $\mathrm{Cr}$ deposition yields smaller nuclei densities which, according to the proposed shadowing mechanism depicted in Fig. 8, would increase the tilt angle of $\mathrm{Cr}$ columns, as observed in Fig. 6. The suggested mechanism is further supported by the findings in Fig. 7. When the deposition of $\mathrm{Cr}$ starts at room temperature, the nuclei density is large, corresponding to the condition of a small tilt angle. As the temperature increases, the resulting column tilt is only found to increase when columns merge with each other (Fig. 7(b)). This indicates that the change in tilt is not caused directly by an increased diffusion of the adatoms, but rather that the geometrical conditions for atomic shadowing change at the new larger column tip.

Greczynski et al. ${ }^{25}$ performed a similar study as the present for off-normally grown $\mathrm{Cr}$ films at a comparable range of $\mathrm{I}_{\mathrm{Tpd}}$ values. In that study, depositions were performed at room temperature in an industrial scale deposition system with a substrate bias of $-150 \mathrm{~V}$. It was found that the Cr columns were raised from $\sim 57^{\circ}$ in the low ionization case (DCMS) towards the substrate normal as $\mathrm{I}_{\mathrm{Tpd}}$ increased. These results contradict those reported in the present study for $\mathrm{Cr}$ films grown without any intentional heating, see Fig. 3. There it is seen that the column tilt is significantly smaller $\left(\sim 27^{\circ}\right)$ independent of the ionization degree, even at the lowest degree of ionization (samples grown by DCMS) where one should expect the deposition flux to be relatively insensitive to the electric field between the plasma and the substrate. There are two possible explanations for this. The first is that Greczynski et al. deposited films at a smaller pressure-distance product (about half of the value used in the present study), which should yield less scattering of the sputtered species in the plasma, leading to an increased column tilt. Another explanation is that the use of a high negative bias together with a large scale system might result in local heating of the substrates by the plasma and thus in a growth temperature above the estimated one $\left(\leq 100^{\circ} \mathrm{C}\right)$. The latter could explain the different results if one accounts for the impact of the growth temperature presented in Fig. 6.

\section{SUMMARY}

$\mathrm{Cu}$ and $\mathrm{Cr}$ films have been grown at various ionization degrees on grounded substrates placed at angle of $90^{\circ}$ with respect to the sputtering source using HiPIMS. The tilt of the columnar microstructure of $\mathrm{Cu}$ has been shown to be uninfluenced by the arrival rate of the deposition flux as well as any possible differences in nucleation characteristics induced by energetic bombardment. Instead, the $\mathrm{Cu}$ columns have been shown to be positioned closer to the substrate surface normal as the ionization degree of the incidence flux increases. Moreover, a large difference in column tilt has been observed between $\mathrm{Cu}$ and $\mathrm{Cr}$, where the $\mathrm{Cr}$ columns are positioned closer to the substrate normal, when grown at room temperature at a low ionization degree. The difference has been shown to decrease and eventually vanish as the homologous temperature during growth of $\mathrm{Cr}$ increases from 0.13 to 0.28 . Adatom diffusion on the columns cannot account for the obtained results and instead, a mechanism based on atomic shadowing at different nucleation characteristics has been suggested. Furthermore, the $\mathrm{Cr}$ column tilt has been found to be affected by the highly ionized fluxes only when certain nucleation characteristics are present.

\section{ACKNOWLEDGMENTS}

V.E. and K.S. acknowledge financial support from Linköping University through the "LiU research fellows" program. The authors should also like to acknowledge Professor Ulf Helmersson for helpful discussions.

${ }^{1}$ M. M. Hawkeye and M. J. Brett, J. Vac. Sci. Technol. A 25, 1317 (2007).

${ }^{2}$ J. J. Steele and M. J. Brett, J. Mater. Sci.: Mater. Electron. 18, 367 (2007).

${ }^{3}$ C. M. Zhou, H. F. Li, and D. Gall, Thin Solid Films 517, 1214 (2008).

${ }^{4}$ A. C. van Popta, J. C. Sit, and M. J. Brett, Proc. SPIE 5464, 198 (2004).

${ }^{5}$ Y. J. Park, K. M. A. Sobahan, J. J. Kim, and C. K. Hwangbo, J. Korean Phys. Soc. 55, 2634 (2009).

${ }^{6}$ M. A. Summers, K. Tabunshchyk, A. Kovalenko, and M. J. Brett, Photonics Nanostruct. Fundam. Appl. 7, 76 (2009).

${ }^{7}$ Y. Zhao, Y. He, and C. Brown, Appl. Phys. Lett. 100, 033106 (2012).

${ }^{8}$ K. Robbie, J. C. Sit, and M. J. Brett, J. Vac. Sci. Technol. B 16, 1115 (1998).

${ }^{9}$ M. Saraiva and D. Depla, J. Appl. Phys. 111, 104903 (2012).

${ }^{10}$ J. M. Garcia-Martin, R. Alvarez, P. Romero-Gomez, A. Cebollada, and A. Palmero, Appl. Phys. Lett. 97, 173103 (2010).

${ }^{11}$ N. G. Nakhodkin and A. I. Shaldervan, Thin Solid Films 10, 109 (1972).

${ }^{12}$ T. Hashimoto, K. Okamoto, K. Hara, M. Kamiya, and H. Fujiwara, Thin Solid Films 91, 145 (1982).

${ }^{13}$ K. Okamoto, T. Hashimoto, K. Hara, M. Kamiya, and H. Fujiwara, Thin Solid Films 147, 299 (1987).

${ }^{14}$ K. Okamoto and K. Itoh, Jpn. J. Appl. Phys., Part 144, 1382 (2005).

${ }^{15}$ M. Holber, S. Logan, H. J. Grabarz, J. T. C. Yeh, J. B. O. Caughman, A. Sugerman, and F. E. Turene, J. Vac. Sci. Technol. A 11, 2903 (1993).

${ }^{16}$ S. Rossnagel, J. Vac. Sci. Technol. B 16, 2585 (1998). 
${ }^{17}$ E. Klawuhn, G. D’Couto, K. Ashtiani, P. Rymer, M. Biberger, and K. Levy, J. Vac. Sci. Technol. A 18, 1546 (2000).

${ }^{18}$ G. C. D'Couto, G. Tkach, K. A. Ashtiani, L. Hartsough, E. Kim, R. Mulpuri, D. B. Lee, K. Levy, M. Fissel, S. Choi, S.-M. Choi, H.-D. Lee, and H.-K. Kang, J. Vac. Sci. Technol. B 19, 244 (2001).

${ }^{19}$ U. Helmersson, M. Lattemann, J. Bohlmark, A. P. Ehiasarian, and J. T. Gudmundsson, Thin Solid Films 513, 1 (2006).

${ }^{20}$ K. Sarakinos, J. Alami, and S. Konstantinidis, Surf. Coat. Technol. 204, $1661(2010)$.

${ }^{21}$ A. Anders, Surf. Coat. Technol. 205, S1 (2011).

${ }^{22}$ D. Lundin and K. Sarakinos, J. Mater. Res. 27, 780 (2012).

${ }^{23}$ J. T. Gudmundsson, N. Brenning, D. Lundin, and U. Helmersson, J. Vac. Sci. Technol. A 30, 030801 (2012).

${ }^{24}$ J. Alami, P. O. A. Persson, D. Music, J. T. Gudmundsson, J. Bohmark, and U. Helmersson, J. Vac. Sci. Technol. A 23, 278 (2005).

${ }^{25}$ G. Greczynski, J. Jensen, and L. Hultman, Thin Solid Films 519, 6354 (2011).

${ }^{26}$ V. Kouznetsov, K. Macak, J. M. Schneider, U. Helmersson, and I. Petrov, Surf. Coat. Technol. 122, 290 (1999).

${ }^{27}$ R. Chistyakov, B. Abraham, W. Sproul, J. Moore, and J. Lin, in Society of Vacuum Coaters 50th Annual Technical Conference Proceedings (Louisville, KY, 2007), pp. 139-143.

${ }^{28}$ J. Alami, S. Bolz, and K. Sarakinos, J. Alloys Compd. 483, 530 (2009).

${ }^{29}$ S. M. Rossnagel and J. J. Cuomo, Thin Solid Films 171, 143 (1989).

${ }^{30}$ D. M. Mattox, in Handbook of Physical Vapor Deposition (PVD) Processing, 2nd ed. (William Andrew, Oxford, 2010), pp. 333-398.

${ }^{31}$ A. Ehiasarian, P. E. Hovsepian, L. Hultman, and U. Helmersson, Thin Solid Films 457, 270 (2004).

${ }^{32}$ J. Alami, K. Sarakinos, F. Uslu, and M. Wuttig, J. Phys. D: Appl. Phys. 42, 015304 (2009).
${ }^{33}$ M. Winter, "WebElements," http://www.webelements.com/, accessed 7 June 2012.

${ }^{34}$ J. Alami, K. Sarakinos, G. Mark, and M. Wuttig, Appl. Phys. Lett. 89, 154104 (2006).

${ }^{35}$ J. Emmerlich, S. Mraz, R. Snyders, K. Jiang, and J. M. Schneider, Vacuum 82, 867 (2008).

${ }^{36}$ K. Van Aeken, S. Mahieu, and D. Depla, J. Phys. D: Appl. Phys. 41, 205307 (2008).

${ }^{37}$ J. F. Ziegler, "The stopping and range of ions in matter," http://www.srim.org, accessed 17 April 2012.

${ }^{38}$ J. T. Gudmundsson, J. Alami, and U. Helmersson, Appl. Phys. Lett. 78, 3427 (2001).

${ }^{39}$ J. Gudmundsson, J. Alami, and U. Helmersson, Surf. Coat. Technol. 161, 249 (2002).

${ }^{40}$ A. Hecimovic, K. Burcalova, and A. P. Ehiasarian, J. Phys. D: Appl. Phys. 41, 095203 (2008).

${ }^{41}$ A. D. Pajdarová, J. Vlček, P. Kudláček, and J. Lukáš, Plasma Sources Sci. Technol. 18, 025008 (2009).

${ }^{42}$ M. Moseler, P. Gumbsch, C. Casiraghi, A. C. Ferrari, and J. Robertson, Science 309, 1545 (2005).

${ }^{43}$ X. W. Zhou and H. N. G. Wadley, Surf. Sci. 431, 42 (1999).

${ }^{44}$ K. Burcalova, A. Hecimovic, and A. P. Ehiasarian, J. Phys. D: Appl. Phys. 41, 115306 (2008).

${ }^{45}$ I. Petrov, P. B. Barna, L. Hultman, and J. E. Greene, J. Vac. Sci. Technol. A 21, S117 (2003).

${ }^{46}$ P. M. Martin, Handbook of Deposition Technologies for Films and Coatings, 3rd ed. (Elsevier Inc, Oxford, 2010).

${ }^{47}$ T. Michely and J. Krug, Islands, Mounds and Atoms: Patterns and Processes in Crystal Growth Far from Equilibrium (Springer, Berlin, 2004). 